\title{
The CRADLE teaching methodology: developing foreign language and entrepreneurial skills in primary school pupils
}

\section{Rebecca Weicht $^{1,2}$ - Irina Ivanova ${ }^{3}$ (D) Ourania Gikopoulou ${ }^{4}$ OD}

Received: 21 August 2020 / Revised: 6 September 2020 / Accepted: 13 September 2020 /

Published online: 28 September 2020

(c) The Author(s) 2020

\begin{abstract}
In recent years, a consensus has grown across the European Union that the acquisition of transversal skills-including foreign language and entrepreneurial skills - is key to the success of learners in their personal and professional life. The CRADLE teaching methodology for primary school teachers is the first teaching methodology to simultaneously foster both of these skill sets, employing a cross-curricular, activity-based, pupil-centred, exploratory teaching and learning approach based on a linear four-step process inspired by Design Thinking with problem-solving and designing solutions in mind. This article discusses the implementation of the CRADLE teaching methodology in six primary schools in three European countries. Based on an analysis of project plans, lesson observations and teachers' feedback during the pilot stage of the methodology, we are able to demonstrate that the methodology is a flexible tool for developing students' knowledge and skills. The observed results provide evidence of increased pupil interest and involvement, successful acquisition of foreign language and communication skills (accuracy and fluency in speaking, vocabulary development, ability to express opinions and ideas, answer questions and understand instructions) and emerging entrepreneurial skills such as self-efficacy, creativity, valuing ideas, taking initiatives, planning and management, and working with others.
\end{abstract}

Keywords Entrepreneurial education · Foreign language · Teaching methodology · Primary school $\cdot$ CLIL $\cdot$ Skills

Rebecca Weicht

r.weicht@mmu.ac.uk

Extended author information available on the last page of the article 


\section{Introduction}

In recent years, a consensus has grown across the European Union that the acquisition of transversal competences-including language learning and entrepreneurial competences - is key to the success of learners in their personal and professional life (European Commission 2016a, b, 2018). Learners must start early to acquire these skills to be sufficiently prepared to enter the labour market. Only then, will they be able to develop higher, more complex skills later. Consequently, there is a need to train primary school teachers to teach transversal competences including entrepreneurial skills.

Similarly, Europe faces a need to increase the number of teachers who are able to participate in students' language education. Already today, teachers and school directors have to make the best possible use of limited resources (European Commission 2016b). Whilst the European Commission has been ambitious in their plans for language learning (European Commission 2008, 2012), time spent on language learning in primary school as a share of the entire curriculum is only a modest 5 to 10\% (Eurydice 2017).

Against this background, the Erasmus+ funded CRADLE project (Creating Activity Designed Language Learning Environments for Entrepreneurship Education) set out to develop a teaching methodology for generalist primary school teachers to foster both entrepreneurial and language learning skills for students aged $8-12$. The project specifically sought to enable generalist teachers with existing knowledge of a foreign language to create environments in their classrooms that foster entrepreneurial and some foreign language skills in learners. Between 2017 and 2020, the project team developed and piloted the CRADLE teaching methodology in six primary schools in three countries (Belgium, Bulgaria, Greece) involving over 200 students. The project partners are specialised in the fields of teacher training, entrepreneurship education and language learning. ${ }^{1}$ The six primary schools were selected to represent differing socio-economic and educational contexts as well as differing language learning specialisations: Uwekind International School (Sofia, Bulgaria) is an international school with a language learning focus on English and German. Ellinogermaniki Agogi (Athens, Greece) is a private school with a focus on English and German. Neue Schule Athen (Athens, Greece) is a newly established school with a focus on German. Unescoschool, De Toverfluit and De Iris (all members of the GO! Scholengroep Brussel) are all public schools in Brussels with

\footnotetext{
1 Goethe-Institut is the Federal Republic of Germany's cultural institution operational worldwide. It has expertise in German language teaching, in the development of training materials, in teacher and trainer training, experience in using action research and the 'Content and Language Integrated Learning' methodology. Shumen University (Bulgaria) is specialised in teacher training. The National and Kapodistrian University of Athens contributed expertise in education evaluation methodologies. The Danish Foundation for Entrepreneurship (FFE) was established as part of the Danish government's strategy to strengthen entrepreneurship teaching in the Danish education system and has become a knowledge centre on entrepreneurship education. Bantani Education (Belgium) is a non-profit specialised in development and delivery of entrepreneurship education programmes. GO! Scholengroep Brussels is a grouping of schools in the Flanders region of Belgium.
} 
students from diverse socio-economic backgrounds. Their language learning focus is French and to a lesser extent, English.

In addition to the materials that make up the CRADLE teaching methodology, which are discussed below, the project has suggested concrete 'Practical Implementation Recommendations' for head teachers and policy makers to help implement the methodology in additional schools in the future. ${ }^{2}$

In the following sections, this paper will outline the CRADLE teaching methodology and then present the findings from piloting the methodology across six primary schools in three countries.

\section{The CRADLE teaching methodology}

The CRADLE teaching methodology was developed as part of the European Union's Erasmus + programme under Key Action 2-Cooperation for Innovation and Exchange of Good Practices, which aims to enable organisations to collaborate in order to improve provision for learners and share innovative practices. It is a triple-focused teaching methodology for primary schools and employs a cross-curricular, activity-based, student-centred, exploratory teaching and learning approach.

The methodology is based on the combination of three key elements-content, language, and entrepreneurship. It provides a model for creating meaningful cycles of lessons based on topics relevant to a variety of curricula and learning outcomes. As a result, teachers can plan a series of lessons evolving around a chosen topic in their curriculum and organise their lessons as a sequence of activities which support and sustain this topic. At the same time, they create environments that support the learning of a foreign language and the acquisition of transversal entrepreneurial competences. The lessons follow in a linear four-step process inspired by Design Thinking with an emphasis on research, problem-solving, prototyping, action, and reflection.

The CRADLE methodology places students' curiosity and initiative at the centre of the learning process. It seeks to foster the development of basic entrepreneurial skills, such as problem-solving, personal responsibility, social responsibility, curiosity, communication, and cooperation, all resulting in self-efficacy and value creation. In its nature, the methodology subscribes to the principles of student-centred instruction and learning by doing, as described within the framework of constructivism in education (cf. Dewey 1938; Vygotsky 1978). This framework puts students' needs and abilities at the centre of the educational process (Brown 2008).

\section{Design thinking and the four-step design process in CRADLE}

CRADLE emulates the iterative approach of design thinking in education. The cycle plan-revise-teach-assess-reflect-adjust aims to engage students in

\footnotetext{
${ }^{2}$ http://www.cradleproject.eu/practical-implementation-recommendations/.
} 
inquiry, promote transfer of learning and helps students to make sense of discrete facts and skills by providing them with a conceptual framework that allows them to uncover the big ideas of content (Wiggins and McTighe 2005). In this process, teachers are seen as coaches and facilitators. They design, plan and support learning, rather than being purveyors of subject knowledge. This approach lends itself to the CRADLE methodology as it builds essential entrepreneurial skills that allow students to be collaborative and inventive.

CRADLE also uses the vehicle of cross-curricular projects that students work on over the course of several weeks. Project-based learning in education has long proved its suitability in developing various aspects of the teaching curriculum in a motivating, student-friendly and accessible way (Thomas 2000; Ivanova 2019).

Building on these two approaches, CRADLE developed a linear four-step activity-designed learning process (ADL), in which students work through the following stages:

1. Prior understanding and research;

2. Ideas generation and design;

3. Prototyping and actions;

4. Evaluation and reflection.

The first step is prior understanding and research. The teacher or the teacher in negotiation with their students (Gibbes and Carson 2014) decides upon a topic of study or problem to address. The topic or problem will then need careful scaffolding by the educator: it must be suitable for students' cognitive level and needs; using an appropriate language level to ensure understanding and basic communication about the topic, and open in its nature to allow students to identify different real-life solutions to the problem. Careful scaffolding is essential at this initial stage of the process in order to provide a balance between supported and independent work (Van de Pol et al. 2010). The process requires the activation of students' prior experiential knowledge, followed by active processing of information obtained through teacher input, guided or independent search of sources, such as study materials, the internet and experts' opinion.

The following two stages are primarily student-led. At the stage of idea generation and design, students respond to an essential question, a problem, scenario, or a topic as outlined in step one producing a large number of ideas and solutions. Idea generation can be organised as a brainstorming activity conducted in groups, as a whole class or individually, taking into consideration students' age, personal qualities and desires and the task complexity. Next, students compare and evaluate their ideas, choosing the one that they consider the best and want to continue working on. The teacher monitors and channels the discussion without judging or imposing their own ideas.

Prototyping, in which students visualise their idea in the form of a drawing, script, model or other creative output, is usually done in groups or teams. The most important outcome of this process is not necessarily the prototype itself, but the interaction using some of the target language, and the skills trained in the 
process of work and negotiation within the teams. When ready, prototypes are presented to a wider audience and the feedback received is used to improve the prototype while at the same time encouraging and motivating the students who created it. The presentation of these prototypes should boost students' self-esteem and sense of achievement.

The final stage is evaluation and reflection. This step supports the development of an ability to assess one's own results, and also to accept the idea of external evaluation as an important part of learning. It could be done both individually and in groups, so that students can learn to be responsible and share their successes and failures. If well organised, this stage can lead to valuable insights and improvements of students' learning and collaboration.

Table 1 outlines the ADL process through an example from the pilot phase. It is a third-grade teacher's planning document for nine lessons for a project on the topic of bees.

Going through the four stages, teachers and students are consistently encouraged to use the target foreign language. It serves both as means of basic communication, for example as language of instruction, and as key vocabulary related to the respective subject area, an approach informed by the instruction paradigm of content and language integrated learning (CLIL).

\section{CLIL and the integration of subject knowledge and foreign language in CRADLE}

One of the main goals of the CRADLE teaching methodology is to create opportunities to develop students' foreign language skills. In order to carve out spaces for language learning in primary schools, CRADLE seeks to create environments supportive of language learning (Cameron 1996). It thus applies the CLIL paradigm which allows for a switch from mother tongue to the target language by both teachers and students.

Subscribing to a philosophy of integration, modernisation and sustainability of education, CLIL is "a generic term to describe all types of provision in which a second language (a foreign, regional or minority language and/or another official state language) is used to teach certain subjects in the curriculum, other than the language lessons themselves" (Eurydice 2006: 8). In other words, a CLIL teacher might teach history in the target foreign language instead of the learners' native language or usual language of classroom interaction. Vice versa, using CLIL might also mean including content from different subject areas into the foreign language lesson. As an approach to teaching, CLIL is particularly suited to the context of integrative cross-curricular learning, as it sees language as a vehicle through which content is learnt and promotes intercultural knowledge and understanding, as well as intercultural communication skills. It integrates language and content in a flexible and dynamic way, without an implied preference for either (Coyle 2006, 2007). Teachers piloting the CRADLE methodology decided at their own discretion when to deliver CRADLE 'lessons'. In some schools, they were part of foreign language lessons; in other schools, teachers used teaching hours they had the discretion to use as they saw fit to work on CRADLE projects. Consequently, CLIL provides opportunities to 
Table 1 Example of the four-step ADL process in practice

Example The world of bees

School Neue Schule Athen, Athens, Greece

Grade/age 3rd grade, 8 years old

Number of students in class 18

\author{
Foreign language level A1 German \\ Content areas content related to the subject of \\ Natural Science, Foreign Language, Arts and \\ Crafts \\ Number of lessons in project 9
}

Prerequisites/requirements in terms of subject knowledge, cognitive and language skills

Subject knowledge Students should be familiar with common insects and should know basic details (e.g. that all insects have 6 legs, that many of them have wings, etc.). They should also have basic knowledge of the stages in the life circle of some common insects (e.g. egg-caterpillar-cocoonbutterfly), be familiar with the concept of ecosystems and understand the importance of insects for nature and humans

Cognitive skills Students should be able to distinguish between knowledge of something, and feelings about something. They should also be able to express their opinion, make suggestions, argue, and justify their choices (in their first language)

Language skills (in terms of foreign language-German) Students should be familiar with basic vocabulary for describing insects. They should also be able to understand basic oral and written instructions, to read and understand simple sentences and questions as well as to formulate short oral or written sentences and questions

Prior understanding and research

Idea generation and design

First, students will reflect on their own feelings and concepts about bees. Then, they will expand their prior knowledge by sharing it through a quiz with the whole class. Parallel to this, students will learn to express themselves while talking about bees in the foreign language by learning new topic-related vocabulary. In addition, students will have input which will further stimulate their curiosity about bees. They will find answers to the questions arising from that process themselves in groups and will share them through presentations in class. Students will gradually recognise the importance of bees for the ecosystem and for humans through pollination. By encountering real examples of areas where bees are extinct, students will realise the negative impact humans have on bee populations, thus putting humanity's future in danger. Within that context, students decide to take action in order to help bees

Students decide how they want to help bees within the school setting. They develop several ideas and after choosing the idea which they think will work best, they work out a relevant plan to implement their idea. In this pilot, school students decided to plant flowers. They found hyacinths to be a reasonable choice, because students could plant them easily. They also are colourful aromatic flowers which easily attract bees 
Table 1 (continued)

Example The world of bees

Prototyping and actions

Students implement their ideas by preparing and carrying out what they have planned. In this school, students took action by planting hyacinths in the school's garden. For 2 months, they were responsible for watering and caring for them during school breaks. As part of another CRADLE project in the same school, the students also organised a spring bazaar. For this bazaar, the students decided to sell the hyacinths. By selling the hyacinths, students "spread" their flowers all over Athens, thus creating "multiple chances" for bees to collect nectar

Evaluation and reflection

Students compared their feelings about bees at the end of the project with the feelings they had had at the beginning. They reflected on their experiences and the knowledge gained from the project. They also noted down what they liked and disliked about the project

study the project-related content from different perspectives without requiring extra teaching hours.

The philosophy of CLIL is based on the integration of the ' $4 \mathrm{Cs}$ '-content, communication, cognition and culture which define teaching aims and learning outcomes (Coyle et al. 2010). In terms of communication, CLIL relies on the interrelation of BICS (Basic Interpersonal Communicative Skills) for less cognitively demanding tasks, and Cognitive Academic Language Proficiency (CALP ), for the more demanding subject-specific language, which is required for academic study (Cummins 2001). While BICS is related to identifying specific information, naming objects, matching, and sorting objects into sets, CALP activates cognitive processes such as justifying opinions, forming hypotheses and evaluating evidence. The cognition-related aspect of CLIL is linked to the differentiation of LOTS and HOTS (lower and higher order thinking skills). In the CRADLE methodology, LOTS, such as remembering, understanding, and applying new subject knowledge, are involved in activities which require recognising new vocabulary, classifying, giving examples and comparing objects by using basic or advanced vocabulary. HOTS include skills such as analysing, evaluating, and creative thinking which contribute to the development of reasoning, critical judgment, and generation of new ideas.

There are clear parallels between the stages of a CLIL lesson and the ADL process. As such, the prior understanding and research stage in ADL is similar to triggering previously learnt content and language in CLIL. The idea generation and design stage parallels formulating hypotheses and designing activities in CLIL. Creating prototypes can be related to executing activities and recording observations. Finally, evaluation and reflection in ADL is similar to formulating conclusions and generating transfer. 
The third key element of the CRADLE methodology is the focus on selected entrepreneurial competences which are developed in the process of ADL.

\section{Developing entrepreneurial competences in CRADLE}

CRADLE teaches entrepreneurial skills through entrepreneurial activities (as opposed to teaching about entrepreneurship and for entrepreneurship; Moberg 2014). It builds on The Danish Foundation for Entrepreneurship's model of “teaching that supports the development of entrepreneurial resources, competences and experiences" (Rasmussen and Fritzner 2016: 7).

The CRADLE teaching methodology especially sought to teach the entrepreneurial competences creativity and sense of initiative. It is these two competences that maximise students' learning by involving them in processes which are intrinsically interesting and give them a sense of ownership and achievement. This focus implies that teachers need to be creative themselves while catering for the personal, social, emotional, and intellectual development of the children, and be enthusiastic, energetic and inspired. Creative teaching involves ownership of knowledge and control of teachers' own pedagogy, which means that teachers can choose what methods or combination of methods to employ, and when. There is a wide range of strategies for creative teaching, which emphasise child-centredness: home and school links; revisiting activities and thus developing children's conceptual skills; teaching in the margins; spontaneous reactions; emotional connections; creating atmosphere and tone; stimulating the imagination; developing empathy; devising critical events (Woods and Jeffrey 1996).

In its understanding of creativity and sense of initiative as entrepreneurial competences, CRADLE refers to the European Commission's Entrepreneurship Competence Framework (EntreComp) (Bacigalupo et al. 2016). It proposes a shared definition of entrepreneurship as a competence, with the aim to raise consensus among stakeholders, and to establish a bridge between education and work. The framework comprises of three competence areas: Ideas and Opportunities, Resources, and Into Action, made up of five competences each. The first area focuses on creativity, and more specifically on student's curiosity and ability to develop relevant ideas within a topic, and to imagine desirable future scenarios. The second area stresses the importance of sustaining and developing learners' belief in their own abilities, as well as their willingness to get support from peers, teachers, and parents when this is needed, and recognising communication skills as a desired outcome. The third area involves the competences of basic planning, execution and presentation, taking responsibility for tasks, working alone and with others, respecting peers and coping with uncertainty. The resulting 15 competences are developed along an eight-level progression model. The application of the EntreComp framework to the CRADLE methodology aims to help teachers to ensure that their pupils actually feel that they are involved in planning their own projects, and that they are mastering the topic.

The CRADLE teaching methodology supports teachers working in the three EntreComp areas by offering guidance in the form of strategies and ready-to-use activities. The CRADLE Toolbox contains a checklist for strategies and resources, 
which teachers can consult when planning their projects and selecting or designing activities for their lessons. For example, the area 'Ideas and opportunities' can be supported by using experiment-based activities which stimulate curiosity. It can also be facilitated by creative, open, or challenging tasks and by surprising and unexpected activities which involve several senses simultaneously. When working with such resources, teachers should balance successful experiences with challenging activities in which students learn to work with uncertainty and seek help, advice, and feedback. The area 'Into Action' is supported by involving students in planning and executing projects, and by delegating responsibility, using networks and collaboration inside and outside school. All CRADLE materials are freely available on the project's website.

\section{Cross-curricular projects as an implementation of the CRADLE methodology}

In the CRADLE methodology, project work is the means by which the three key parts are integrated and developed simultaneously. Project-based learning in education has long proved its suitability as a vehicle for developing and strengthening various aspects of the teaching curriculum in a motivating, student-friendly and accessible way. As a rule, project work takes the form of a series of activities, which allow pupils to study, research and achieve results by capitalising on their abilities, interests and personal experiences. When working on projects, learners act by themselves or under the guidance and monitoring of teachers. Extending beyond the classroom, project work is student-centred rather than teacher directed.

Topics chosen for projects can come from different areas of the curriculum. They should be interesting and motivating for students whilst also being at the same time suitably challenging so that learning can take place. In addition, they should "lend themselves to the design of purposeful activities, including opportunities for investigative, factual enquiry and for creative, imaginative work" (Read 2007: 236). Topics covered in CRADLE projects realised during the pilot included among others earthquakes, bees, climate change, healthy eating, leisure, sustainability, music and sports. The projects were delivered over the course of 1 to 3 months. The amount of time spent on CRADLE projects varied between 2 and $4 \mathrm{~h}$ once or twice per week.

Table 2 illustrates the interrelation between the three components of the methodology and the stages through which learning experiences progress:

To support teachers implementing the CRADLE methodology in their own classrooms, the project team developed various tools for teachers. A blended Teacher Training Course provides guidance on how to implement the CRADLE methodology in a variety of teaching contexts. The Toolbox contains tools for lesson observation, a checklist for strategies and resources, and a collection of project plans, prepared by teachers from the pilot schools, which gives teachers ideas on how to implement the methodology in their own context and for their own purposes. The collection of project plans in the Toolbox contains examples of good practices in implementing the CRADLE methodology in a variety of national and institutional contexts. They are flexible and can be adapted to the level and needs of different 


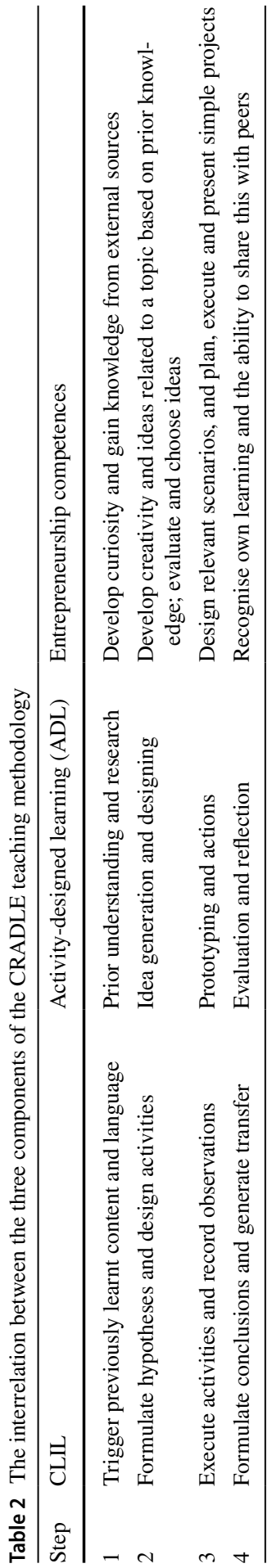


students. The planning templates designed as part of the CRADLE Toolbox contains a project overview, an overview of the stages and lessons in the project and a single lesson plan template. Using these templates, teachers can produce more or less detailed project plans on a variety of topics relevant to their national curricula.

\section{Evaluation and findings}

The CRADLE project set out to develop the CRADLE teaching methodology and tools for teachers as well as pilot the methodology across six primary schools in three countries. An evaluation strategy reliant on quantitative as well as qualitative data addressed several research questions relating to the overall efficacy of the methodology but also practical aspects such as project delivery. The evaluation of this methodology addresses the following four research questions:

$R Q 1$ Do pupils develop their language skills and increase their interest for the target foreign language?

$R Q 2$ Do pupils acquire entrepreneurial skills?

$R Q 3$ Are teachers' profiles strengthened by the acquisition of a new teaching methodology and new skills?

$R Q 4$ Is the CRADLE teaching methodology feasible, implementable, and useful?

\section{Data collection methods}

Data were collected via questionnaires, interviews, and observations. The questionnaires assessed pupils' and teachers' attitudes and perceptions towards the teaching methodology, and foreign language and entrepreneurial skills' acquisition prior to and following the implementation of the CRADLE methodology in the target schools.

The questionnaires reflected commonly used approaches that were adapted to meet the project's research goals (Bacigalupo et al. 2016; European Commission 2013, 2015; Glynn et al. 2009; Jacinta and Zakia 2001; McAuley et al. 1987; McCord and Matusovich 2013; Moberg et al. 2014; Pintrich and Blumenfeld 1985; Plant and Ryan 1985). The questionnaires asked pupils and teachers to score their answers on a 5-point Likert scale ranging from 1 (strongly disagree) to 5 (strongly agree). A total of 202 pupils and 9 teachers completed the questionnaires. To assess the impact of the CRADLE teaching methodology, paired sample $t$-tests were applied to pupils' questionnaires.

In addition, a representative number of pupils were interviewed $(n=54)$. The interviews examined pupils' likes, dislikes, and difficulties during the implementation of CRADLE.

Finally, in situ observations took place both in the beginning and near the end of the pilot year to evaluate the projects' progress, as well as feasibility, success, and usability of the teaching methodology. These on-site visits provided the opportunity to observe how the methodology was implemented during the lessons and 
collect feedback directly from teachers and students concerning the methodology, the selected 'CRADLE projects', the difficulties they encountered, their likes, etc.

The pre-intervention questionnaires to evaluate pupils' attitudes, perceptions and skills acquisition examined the following factors: interest/enjoyment (6 questions), tension/pressure (6 questions), value/usefulness (6 questions), perceived competence in the foreign language ( 5 questions), perceived competence in CRADLE (4 questions), self-awareness and self-efficacy (5 questions), creativity (6 questions), valuing ideas (5 questions), taking initiative (5 questions), planning and management (5 questions), coping with uncertainty and risk (5 questions), working with others (5 questions) and lesson/teacher assessment by pupils (6 questions). In order to avoid random answering, some reverse questions were added in most factors (e.g. "learning a foreign language is fun" and "learning a foreign language is boring") and for these questions the scoring was also reversed. At the final version of the questionnaires, the identification of factors was removed, and the questions were placed in random order. A reliability analysis was also carried out. The Cronbach's alpha coefficient showed the questionnaire to reach acceptable reliability, $\alpha=0.83$. All items appeared to be worthy of retention, resulting in a decrease in the alpha if deleted.

The first three factors included separate questions for CRADLE and the foreign language and a score for each pupil was calculated separately. The total score for each pupil in each factor was calculated by adding all the scores of the questions of each factor (e.g. for the factor working with others that consisted of 5 questions the maximum total score for a pupil would be $5 \times 5$ questions $=25$ points). Since the number of the questions was not the same for all factors, in order to have a common scale and make comparisons, the scores were converted into percentages to be used for the graphs.

The same procedure was followed for the post-intervention questionnaire. In addition to the 69 questions of the pre-intervention questionnaire, it included 13 additional questions (consisting of YES or NO answer options) concerning pupils' self-assessment and satisfaction with the methodology. The pupils' questionnaires (both pre and post) also included 16 questions to be answered by their teachers to evaluate their performance and skills in the foreign language and entrepreneurship using again a 5-point Likert scale ranging from 1 (inadequate) to 5 (excellent).

Teachers' attitudes, perceptions and skills acquisition before application of the CRADLE methodology were measured in the same manner. The following factors were examined: interest/enjoyment (6 questions), tension/pressure (3 questions), competence (3 questions), methodology implementation and strategies enhancing pupils' skills (11 questions) and teachers' skills (12 questions) with regard to creativity, valuing ideas, coping with uncertainty and risk, taking initiative, working with others, planning and management. The post-intervention questionnaire included an additional 26 questions about pupils' assessment and teachers' satisfaction with the methodology. The Cronbach's alpha coefficient showed the questionnaire to reach acceptable reliability, $\alpha=0.71$.

Following data processing and statistical analyses, the results were summarised and analysed by each factor. 
Table 3 Outcomes of the paired sample $t$-tests

\begin{tabular}{llllll}
\hline & \multicolumn{2}{l}{ Mean (average percentage) } & & \\
\cline { 2 - 3 } Factor & Pre-treatment & Post-treatment & & $t$ & $p$-value \\
\hline Interest/enjoyment & 84.5 & 89.8 & -6.109 & $0.001^{* * *}$ \\
Tension/pressure & 39.6 & 38.3 & 0.986 & 0.325 \\
Value/usefulness & 84.8 & 89.9 & -5.077 & $0.001^{* * *}$ \\
Perceived competence & & & & \\
FL & 76.8 & 80.0 & -3.030 & $0.003^{* * *}$ \\
CRADLE & 81.7 & 84.3 & -2.228 & $0.027^{* *}$ \\
$\quad$ Total & 78.9 & 82.1 & -3.340 & $0.001^{* * *}$ \\
Self-efficacy & 79.2 & 82.0 & -2.272 & $0.024^{* *}$ \\
Valuing ideas & 81.1 & 83.3 & -2.021 & $0.045^{* *}$ \\
Creativity & 78.5 & 81.5 & -2.281 & $0.018^{* *}$ \\
Taking initiative & 65.7 & 68.2 & -2.289 & $0.023^{* *}$ \\
Planning & 78.6 & 80.8 & -2.014 & $0.045^{* *}$ \\
Coping uncertainty & 75.2 & 77.2 & -1.404 & 0.162 \\
Working with others & 78.6 & 81.6 & -2.222 & $0.027^{* *}$ \\
\hline
\end{tabular}

$* p<10 \%, * * p<5 \%, * * p<1 \%$

\section{Findings}

Addressing RQ1 and RQ2, a series of analyses were performed: first, paired samples $t$-tests (2-tailed) of 202 pupils' responses showed statistically significant improvement in pupils' attitudes and in self-perception of their skills following their work on CRADLE projects as shown in Table 3.

As shown in Table 3, the greatest improvements were observed in the factors: interest/enjoyment, value/usefulness, perceived competence, and creativity. Only in two instances-tension/pressure and coping with uncertainty-was a positive but statistically insignificant difference identified between the pre- and post-treatment groups.

Secondly, the statistical analysis of pupils' skills and progression in learning with respect to their foreign language and entrepreneurial skills was complemented by an analysis of teachers' assessments of their students' skills.

Some significant results based on pupils' answers to the relevant questions of their post-questionnaires (self-assessment) include that

- $94 \%$ of pupils felt that CRADLE helped them come up with new ideas;

- $89 \%$ of pupils felt they were able to recognise good ideas expressed by their classmates;

- $88 \%$ of pupils felt that CRADLE helped them gain confidence in themselves;

- $86 \%$ of pupils felt they can express themselves in the foreign language more easily; 


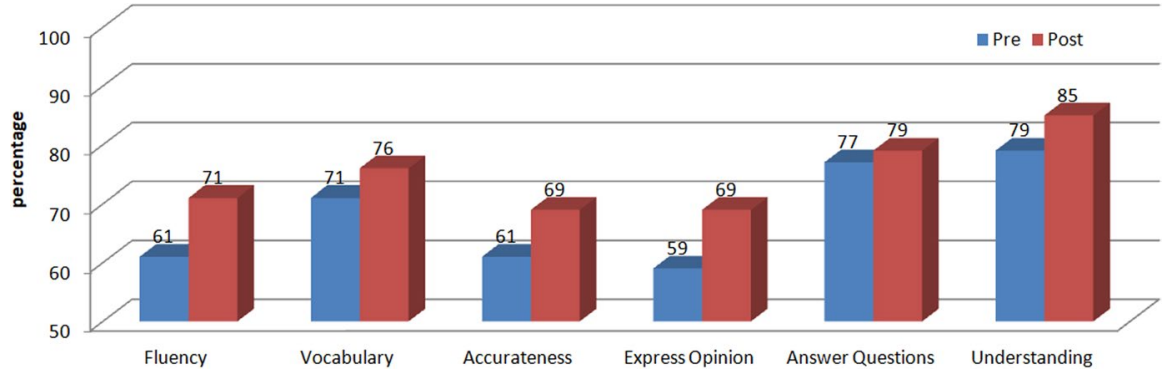

Fig. 1 Comparison of pupils' performance and foreign language skills before and after the implementation of CRADLE (\%)

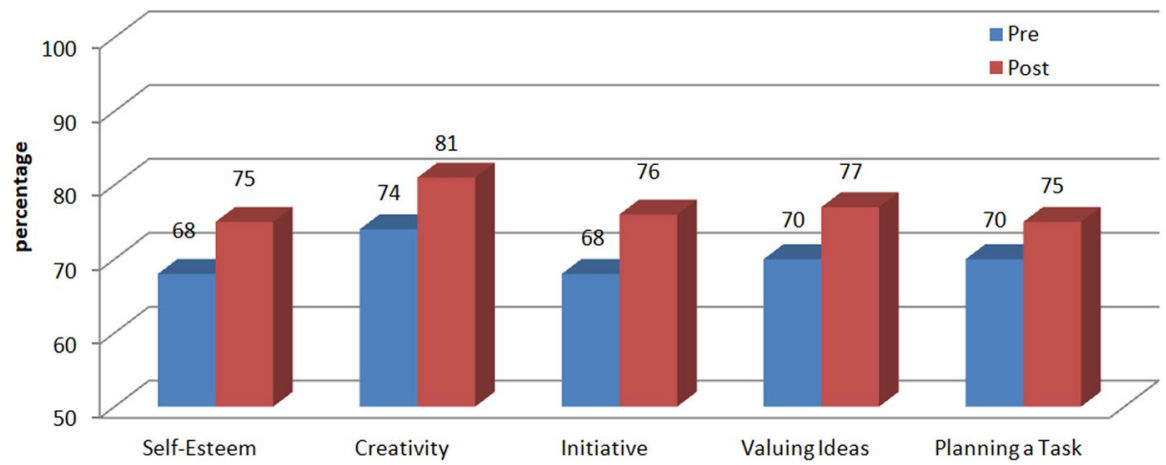

Fig. 2 Comparison of pupils' performance and entrepreneurial skills before and after the implementation of CRADLE (\%)

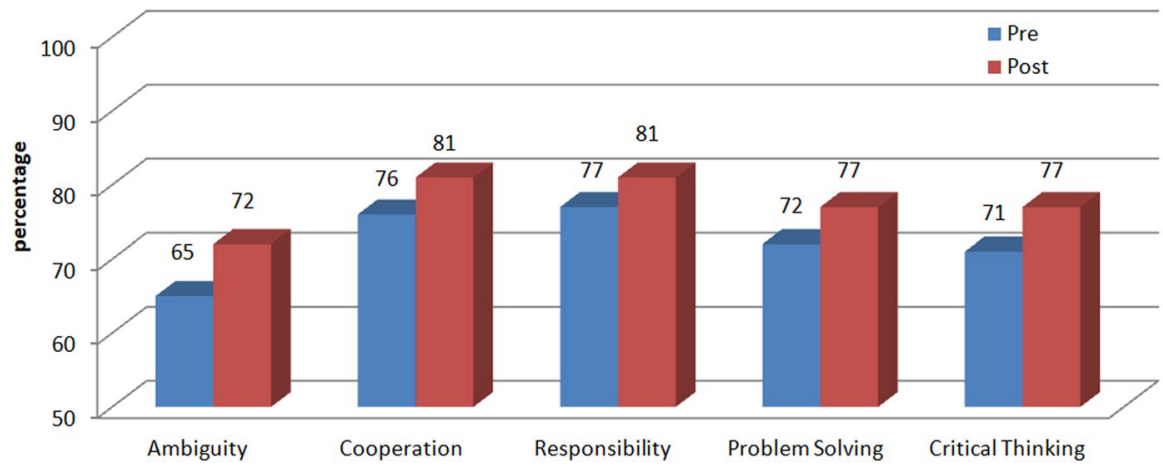

Fig. 3 Comparison of pupils' performance and entrepreneurial skills before and after the implementation of CRADLE $(\%)$

- $85 \%$ of pupils felt they can work with other members of their team more easily than before. 
These results seem to be confirmed by teachers' assessment of pupils' skills through the 16 relevant questions included in the pupils' questionnaires.

The paired samples $t$-tests showed statistically significant improvement in all areas measured, as shown in Figs. 1 and 2.

With regard to pupils' foreign language skills, CRADLE was successful in the enhancement of students' fluency and accuracy in speaking and ability to express their opinion (Fig. 3).

Paired samples $t$ test: fluency in speaking FL: $t(201)=-6.416, p<0.001$; vocabulary development in FL: $t(201)=-3.959, p<0.001$; Accurateness in speaking FL: $t(201)=-6.089, p<0.001$; Ability to express their opinion in FL: $t(201)=-6.142, p<0.001$; ability to answer questions in FL: $t(201)=-4.143$, $p<0.001$; ability to understand instructions in FL: $t(201)=-3.742, p<0.001$.

With regard to students' entrepreneurial skills a greater improvement was observed in their self-confidence, creativity, taking initiative, valuing ideas and critical thinking.

Paired samples $t$-test: self-esteem: $t(201)=-5.165, p<0.001$; creativity: $t(201)=-4.958, p<0.001$; taking initiative: $t(201)=-4.753, p<0.001$; valuing ideas: $t(201)=-4.364, p<0.001$; planning a task: $t(201)=-3.879, p<0.001$.

Paired samples $t$-test: dealing with ambiguity/uncertainty: $t(201)=-4.542$, $p<0.001$; cooperating with other students: $t(201)=-4.066, p<0.001$; responsibility: $t(201)=-3.291, p=0.001$; problem-solving: $t(201)=-3.451, p<0.001$; critical thinking: $t(201)=-4.801, p<0.001$.

In addressing RQ4, the additional questions of the post-intervention questionnaires revealed pupils' satisfaction with the methodology and their assessment of the project. The majority of pupils found their CRADLE lessons more interesting than at the beginning of the year (86\%), they considered CRADLE lessons more interesting than their other lessons $(80 \%)$, and they had no difficulty understanding the teacher's instructions delivered in the foreign language (84\%). Their teacher encouraged discussion and debate in class (77\%), and their teacher listened to their ideas $(81 \%)$. However, with regard to continuity, the most important result was that $93 \%$ of pupils answered that they would like to participate in CRADLE projects again the following year.

The interviews revealed that the students particularly enjoyed working in groups, being creative and exchanging ideas, and presenting their work. In their own words, they described their work as 'we invent ways to change the world' and that 'CRADLE gives you the chance to learn without books and grammar exercises. Everyone can be an excellent student with CRADLE'. They also felt that 'every student in the class participates in something and no one is left out'. In fact, most pupils could not find anything negative to say about their participation in CRADLE except a few pupils who mentioned that they did not like it when their proposed idea for a project was not chosen by their peers. Students' difficulties mostly related to choosing among a variety of ideas, finding a way to transform an idea into an action with economic, cultural, or social value, generating ideas and the lack of time. They instead asked for more CRADLE lessons per week and that the CRADLE approach be used in other subjects too. They also 
Table 4 Comparison of teachers' assessments of their entrepreneurial skills before and after the implementation of CRADLE

\begin{tabular}{llr}
\hline Teachers' assessment of their entrepreneurial skills & Pre (\%) & Post (\%) \\
\hline I am able to come up with new and different solutions to a problem & 45 & 67 \\
I give my pupils freedom during the lesson & 67 & 89 \\
I have no difficulty in breaking norms and traditions & 77 & 100 \\
I am capable of imagining how we can make things work & 78 & 89 \\
I incorporate activities allowing pupils to act spontaneously & 56 & 67 \\
I encourage my pupils to find new solutions to a problem & 84 & 92 \\
I encourage my pupils to ask questions & 82 & 96 \\
I encourage my pupils to try something new & 82 & 87 \\
I ask pupils to explain their ideas or how they reached their answer & 78 & 88 \\
I encourage discussion and debate in class & 88 & 100
\end{tabular}

proposed to organise an international event with all CRADLE pilot schools to showcase their work.

The positive assessment of CRADLE in these comments was confirmed by the in situ visits. The general impression was that the methodology was implemented with great success in all six schools and that pupils showed interest and participated willingly and responded successfully to activities. They showed great enthusiasm and seemed to enjoy themselves. They cooperated harmoniously in smaller and larger groups and used the target foreign language during the CRADLE classes.

Addressing research question RQ3, a shortcoming of the evaluation is that the study suffers from a small sample as only nine teachers implemented the CRADLE methodology in their classes. However, the data showed that teachers have strengthened their profiles through the acquisition of a new teaching methodology and the enhancement of their skills. Namely, the questionnaires showed that teachers improved their own entrepreneurial skills, as shown in Table 4.

This impression was confirmed in observations where teachers showed considerable enthusiasm for the classes.

Lastly, in addressing research question RQ4, teachers found the CRADLE lessons to be pleasant (100\%), that the CRADLE methodology increased pupils' interest (67\%), improved pupils' cooperation (78\%), improved pupils' cooperation (78\%), improved pupils' performance in the foreign language (78\%) and enhanced pupils' self-confidence (100\%), as well as creativity (100\%). All teachers who participated would recommend CRADLE to other colleagues and most of them answered that they would like to use CRADLE again the following year (89\%) since they found their classes fulfilling and enjoyable.

Moreover, teachers found the tools developed by the CRADLE project to be very useful. They evaluated the teacher training course as very useful as it helped them to better understand Activity Designed Learning, CLIL, and entrepreneurial competences. 
The interview data highlighted specifically that teachers learnt to trust their pupils and were positively surprised to see how competent pupils are without being given the responsibility to complete a task on their own. One of the main difficulties for teachers was scaffolding of the appropriate entrepreneurial skill when developing the CRADLE projects. This was more the case in the beginning of the pilot and improved during the implementation of the CRADLE methodology.

\section{Discussion}

Overall, the results were positive and encouraging as a statistically significant improvement of participants' attitudes, motivation and skills was observed.

Addressing research questions RQ1 and RQ2, we found consistent evidence that suggests CRADLE is effective at increasing pupils' skills across a variety of competences both in the foreign language as well as entrepreneurial skills. Addressing RQ3, our data showed a strengthening of teachers' profiles through the acquisition of a new teaching methodology and enhancement of their skills. Regarding RQ4, the data collected from the additional questions of the post-intervention questionnaires as well as from the interviews and the in situ observations revealed the feasibility, applicability, and usefulness of the CRADLE methodology. Both pupils and teachers expressed their satisfaction with the methodology, found CRADLE lessons pleasant and participated with increased interest and enthusiasm.

In paving the way for a wider dissemination of the CRADLE teaching methodology, the project consortium also collated 'Practical Implementation Recommendations' to support interested teachers and head teachers in taking up the methodology in their classrooms and schools. They also sought to illustrate to policy makers what benefits the CRADLE methodology can bring by embedding teaching focussed on skills building in the wider school community. These recommendations outline good practice learnings from the pilot on school policy (e.g. school policy should support teaching with a flexible timetable and cooperation between teachers and external partners), and the teacher mindset (teachers ought to be open-minded and studentcentred, their social and emotional skills are imperative for student improvement) that teachers should have a growth-mindset. The PIR outline the teacher role as facilitator rather than 'sage on the stage' (King 1993) and give experiences on teachers' experience in classroom management and infrastructure (e.g. classroom setup). ${ }^{3}$

Some limitations around the teaching methodology and data collection remain, however. Some constraints on the value and generalisability of the findings regarding the effectiveness of the CRADLE methodology were imposed by the fact that we operated mainly with self-reported data, which are difficult to verify due to the lack of more 'objective' tools for measuring achievement, such as language tests, for example. In addition, the subjective nature of the derived data might have resulted

\footnotetext{
${ }^{3}$ http://www.cradleproject.eu/wp-content/uploads/2019/09/practical-implementation-reccomendations .pdf.
} 
in an overemphasis on the positive aspects of students' and teachers' experiences in the study. Further longitudinal studies of both qualitative and quantitative type are needed to confirm the effectiveness of the proposed methodology and its applicability to various teaching and learning contexts. With regard to the data collected, the results reported herein should be considered in the light of the limitation of the small sample of teachers. Despite the large number (202) of participating students only 9 teachers participated in the project. This small sample of teachers cannot be considered representative and statistical analyses generalised to a larger population cannot be performed.

In summary, the findings show that the CRADLE teaching methodology meets both its stated goals to simultaneously foster the development of foreign language and entrepreneurial skills in primary school pupils aged 8 to 12 . At the same time, it provides teachers, head teachers and education policy makers with a teaching methodology that addresses the issue of limited resources by allowing generalist teachers with a basic understanding of a foreign language to create environments that offer room for language learning and developing entrepreneurial skills. CRADLE's linear process allows teachers to achieve both aims of fostering entrepreneurial skills such as independence and inquiry while building environments in which learners engage with the target foreign language. Through teachers' primary role in scaffolding the learning process while students are proactive in their learning and inquiry, students are motivated and engaged. Students' participation in the process allows them to build valuable experiences appropriate to their age and cognitive capacity. The evidence of learners' success is revealed in their performance: they were able to transfer knowledge and skills effectively to a variety of real-life situations; learn how to explain, interpret, apply, shift perspective, empathise, and reflect with minimum scaffolding and prompting.

\section{Conclusion}

The CRADLE project set out to develop and test a teaching methodology for generalist primary school teachers to simultaneously foster foreign language and entrepreneurial skills in pupils aged 8 to 12 . Over the course of 3 years, the project consortium developed a teaching methodology including tools that teachers can apply across different curricula and in different classrooms to teach different target foreign languages. The team piloted the methodology in a variety of socio-economic and educational contexts as well as differing language learning specialisations.

The CRADLE methodology is based on the combination of three key elementscontent, language, and entrepreneurship. It is a linear four-step activity-designed learning process, in which students work through the stages of (1) prior understanding and research, (2) ideas generation and design; (3) prototyping and actions; and (4) evaluation and reflection. Project work through which the methodology is delivered fosters authentic integration of entrepreneurial and language skills through mirroring real-life tasks. It is motivating, stimulating and empowering for learners and results in enhanced communication skills, knowledge about the subject, cognitive 
abilities, self-confidence, and other important life skills, including entrepreneurial skills and emergent learner autonomy, as we will see now.

The evaluation of the project shows the teaching methodology to be successful in fostering both foreign language as well as entrepreneurial skills. Pupils' fluency and accuracy in speaking and ability to express their opinion improved, as did their self-confidence, creativity, ability to take the initiative, value ideas and critical thinking. Pupils also approached CRADLE lessons with increased interest and involvement. Teachers found that CRADLE made their classes more fulfilling, interesting, enjoyable, strengthened their profiles and also enhanced their own foreign language as well as entrepreneurial skills. The CRADLE teaching methodology seems to be feasible and implementable as well as useful and eventually successful, contributing to a more interesting and fun lesson for learners that enhances both foreign language and entrepreneurial skills.

The results of our study are quite encouraging urging us as educators to promote the adoption of the CRADLE methodology in more schools. Our work adds to previous studies exploring the ways of improving the learning process by motivating students and raising their interest in foreign languages as well as acquiring entrepreneurial skills.

Acknowledgements The authors are grateful for feedback on earlier versions of this paper to Stuart Mills and Bea Matz, the editor of this issue as well as anonymous referees.

Authors' contributions Not applicable.

Funding The "CRADLE" project has been co-funded with support of the European Union's Erasmus + programme; funding ID: VG-IN-BY-17-035544.

Data availability Not applicable.

\section{Compliance with ethical standards}

Conflicts of interest No conflict of interest.

Code availability Not applicable.

Open Access This article is licensed under a Creative Commons Attribution 4.0 International License, which permits use, sharing, adaptation, distribution and reproduction in any medium or format, as long as you give appropriate credit to the original author(s) and the source, provide a link to the Creative Commons licence, and indicate if changes were made. The images or other third party material in this article are included in the article's Creative Commons licence, unless indicated otherwise in a credit line to the material. If material is not included in the article's Creative Commons licence and your intended use is not permitted by statutory regulation or exceeds the permitted use, you will need to obtain permission directly from the copyright holder. To view a copy of this licence, visit http://creativecommons.org/licen ses/by/4.0/. 


\section{References}

Bacigalupo, M., Kampylis, P., Punie, Y., \& Van den Brande, G. (2016). EntreComp: The entrepreneurship competence framework. Luxembourg: Publication Office of the European Union.

Brown, J. (2008). Student-centered instruction: Involving students in their own education. Music Educators Journal, 94(5), 30-35.

Cameron, L. (1996). English language development across the curriculum in multilingual primary classrooms. In R. Webb (Ed.), Cross-curricular primary practice: Taking a leadership role (pp. 60-79). London: The Falmer Press.

Coyle, D. (2006). Content and language integrated learning. Motivating learners and teachers. https:// blocs.xtec.cat/clilpractiques1/files/2008/11/slrcoyle.pdf. Accessed 12 June 2020.

Coyle, D. (2007). Content and language integrated learning: Towards a connected research agenda for CLIL pedagogies. International Journal of Bilingual Education and Bilingualism., 10(5), 543-562.

Coyle, D., Hood, P., \& Marsh, D. (2010). CLIL: Content and language integrated learning. New York: Cambridge University Press.

Cummins, J. (2001). Negotiating Identities: Education for empowerment in a diverse society (2nd ed.). Los Angeles: California Association for Bilingual Education.

Dewey, J. (1938). Experience and education. New York: Macmillan Company.

European Commission (2008). Communication from the Commission to the European Parliament, the Council, the European Economic and Social Committee and the Committee of the RegionsMultilingualism: an asset for Europe and a shared commitment. https://eur-lex.europa.eu/legal -content/EN/TXT/?uri=celex:52008DC0566. Accessed 13 August 2020.

European Commission (2012). Language competences for employability, mobility and growth. https ://eur-lex.europa.eu/legal-content/EN/TXT/PDF/?uri=CELEX:52012SC0372\&from=NL. Accessed 13 August 2020.

European Commission (2013). Entrepreneurship Education: A Guide for Educators. http://ec.europ a.eu/DocsRoom/documents/7465/attachments/1/translations/en/renditions/native\&usg=AFQjC NEAZENuwg06uXIDQR_CK8zmSko5Lw\&sig2=kjtnBVqQOeVNEhNWeBUSrw\&cad=rja. Accessed on 13 August 2020.

European Commission (2015). Entrepreneurship Education: A road to success, A compilation of evidence on the impact of Entrepreneurship education strategies and measures. https://ec.europa.eu/ growth/content/entrepreneurship-education-road-success-0_en. Accessed 13 August 2020.

European Commission (2016a). Communication on "A New Skills Agenda for Europe". https:// ec.europa.eu/transparency/regdoc/rep/1/2016/EN/1-2016-381-EN-F1-1.PDF. Accessed 13 August 2020.

European Commission (2016b). Communication on "Improving and Modernising Education". https ://eur-lex.europa.eu/legal-content/EN/TXT/?uri=COM\%3A2016\%3A941\%3AFIN. Accessed 13 August 2020.

European Commission (2018). Council Recommendation of 22 May 2018 on key competences for lifelong learning. https://eur-lex.europa.eu/legal-content/EN/TXT/?uri=urise rv\%3AOJ.C_.2018.189.01.0001.01.ENG\&toc=OJ\%3AC\%3A2018\%3A189\%3ATOC. Accessed 13 August 2020.

Eurydice (2006). Content and Language Integrated Learning (CLIL) at School in Europe. Eurydice Report. Luxembourg: Publications Office of the European Union.

Eurydice. (2017). Key data on teaching languages at school in Europe-2017 edition. eurydice report. Luxembourg: Publications Office of the European Union.

Gibbes, M., \& Carson, L. (2014). Project-based language learning: An activity theory analysis. Innovation in Language Teaching and Learning, 8(2), 171-187.

Glynn, S., Taasoobshirazi, G., \& Brickman, P. (2009). Science motivation questionnaire: Construct validation with nonscience majors. Journal of Research in Science Teaching, 46(2), 127-146.

Ivanova, I. (2019). Project work as a vehicle for developing foreign language and entrepreneurship skills. BETA E-newsletter, 42, 39-54.

Jacinta B.-T.,\& Zakia R. (2001). Logic models and outcomes for youth entrepreneurship programs, Report to the DC Children and Youth Investment Trust Corporation.

King, A. (1993). From sage on the stage to guide on the side. College Teaching, 41(1), 30-35. 
McAuley, E., Duncan, T., \& Tammen, V. V. (1987). Psychometric properties of the Intrinsic Motivation Inventory in a competitive sport setting: A confirmatory factor analysis. Research Quarterly for Exercise and Sport, 60, 48-58.

McCord R., \& Matusovich H., (2013). Developing an instrument to measure motivation, learning strategies and conceptual change, In 120th ASEE annual conference \& exposition, Atlanta, 23-26 June 2013.

Moberg, K. (2014). Assessing the impact of entrepreneurship education: From ABC to PhD. PhD dissertation, Copenhagen Business School, Department for strategy and globalization. https://www. cbs.dk/files/cbs.dk/call_to_action/enter4-assessing_the_impact_of_entrepreneurship_educationfrom_abc_to_phd.pdf. Accessed 10 June 2020.

Moberg, S.K., Vestergaard, L., Fayolle, A., Redford, D., Cooney, T., Singer, S., Sailer, K. \& Filip, D. (2014). How to assess and evaluate the influence of entrepreneurship education. Report for the ASTEE project-assessment tool and indicators for entrepreneurship education.

Pintrich, P. R., \& Blumenfeld, P. C. (1985). Classroom experience and children's self-perceptions of ability, effort, and conduct. Journal of Educational Psychology, 77(6), 646-657.

Plant, R. W., \& Ryan, R. M. (1985). Intrinsic motivation and the effects of self-consciousness, selfawareness, and ego-involvement: An investigation of internally-controlling styles. Journal of Personality, 53, 435-449.

Rasmussen, A., \& Fritzner, A. (2016). From dream to reality. Learning outcomes and didactic principles for teaching entrepreneurship in Nordic schools. Copenhagen: Nordic Council of Ministers.

Read, C. (2007). 500 activities for the primary classroom. Oxford: Macmillan Books for teachers.

Thomas, J. W. (2000). A review of research on project-based learning. https://www.nido.cl/uploaded/ pblresearch2.pdf. Accessed 13 August 2020.

Van de Pol, J., Volman, M., \& Beishuizen, J. (2010). Scaffolding in teacher-student interaction: A decade of research. Educational Psychology Review, 22, 271-297.

Vygotsky, L. S. (1978). Mind in society: The development of higher psychological processes. Cambridge, Mass.: Harvard University Press.

Wiggins, G., \& McTighe, J. (2005). Understanding by design. Expanded (2nd ed.). USA: ASCD publications.

Woods, P., \& Jeffrey, B. (1996). Teachable moments: The art of creative teaching in primary schools. Buckingham: Open University Press.

Publisher's Note Springer Nature remains neutral with regard to jurisdictional claims in published maps and institutional affiliations.

\section{Affiliations}

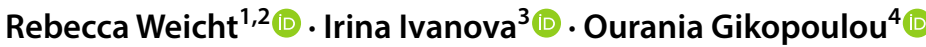

Irina Ivanova

iraivshu@yahoo.com

Ourania Gikopoulou

gikopoulou@gmail.com

1 Present Address: Bantani Education, Brussels, Belgium

2 Manchester Metropolitan University, Manchester, UK

3 Department of English Studies, University of Shumen, Varna, Bulgaria

4 National and Kapodistrian University of Athens, Athens, Greece 